\title{
H-Bond Self-Assembly: Folding versus Duplex Formation
}

Diego Núñez-Villanueva, Giulia Iadevaia, Alexander E. Stross, Michael A. Jinks, Jonathan A. Swain, and Christopher A. Hunter*(i)

Department of Chemistry, University of Cambridge, Lensfield Road, Cambridge CB2 1EW, U.K.

Supporting Information

ABSTRACT: Linear oligomers equipped with complementary H-bond donor (D) and acceptor (A) sites can interact via intermolecular $\mathrm{H}$-bonds to form duplexes or fold via intramolecular H-bonds. These competing equilibria have been quantified using NMR titration and dilution experiments for seven systems featuring different recognition sites and backbones. For all seven architectures, duplex formation is observed for homo-sequence 2-mers (AA.DD) where there are no competing folding equilibria. The corresponding hetero-

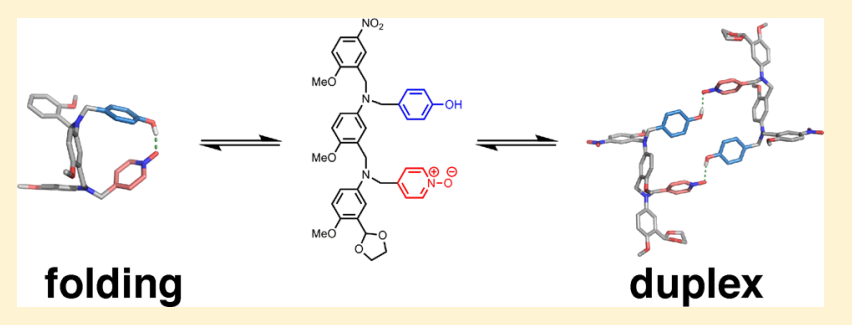
sequence $\mathrm{AD}$ 2-mers also form duplexes, but the observed self-association constants are strongly affected by folding equilibria in the monomeric states. When the backbone is flexible (five or more rotatable bonds separating the recognition sites), intramolecular $\mathrm{H}$-bonding is favored, and the folded state is highly populated. For these systems, the stability of the $\mathrm{AD} \cdot \mathrm{AD}$ duplex is 1-2 orders of magnitude lower than that of the corresponding AA.DD duplex. However, for three architectures which have more rigid backbones (fewer than five rotatable bonds), intramolecular interactions are not observed, and folding does not compete with duplex formation. These systems are promising candidates for the development of longer, mixed-sequence synthetic information molecules that show sequence-selective duplex formation.

\section{INTRODUCTION}

Macromolecules of defined sequence form the molecular basis for living systems. Selective base pairing allows the sequence information stored in nucleic acid polymers to be read and translated through template synthesis. ${ }^{1}$ The sequences of proteins and nucleic acids determine how they fold into three-dimensional structures, which in turn dictate the structural, recognition, and catalytic properties that govern the biochemistry of the cell. ${ }^{2}$ Synthetic supramolecular systems that recapitulate the sequence-selective recognition or folding properties of biomacromolecules are beginning to appear, and in the long term, synthetic information molecules may be expected to offer alternatives to proteins and nucleic acids, where sequence can be used to program function. Nucleic acids are unique in that they combine both duplex-forming and folding properties. The double-stranded structures are the basis for replication, and folded single strands act as receptors and catalysts, so it is possible to use nucleic acids in directed evolution experiments to obtain functional polymers. ${ }^{3}$ The balance between folding and duplex formation in nucleic acids is therefore thought to be critical in the evolution of living systems. ${ }^{4}$ In this Article, we examine the interplay of folding and duplex formation in prototype synthetic molecules.

Inspired by DNA, researchers have put considerable effort into synthetic supramolecular systems that form duplex structures held together by non-covalent interactions. ${ }^{5-7}$ Although programmable sequence-specific recognition of DNA has been achieved with synthetic molecules, ${ }^{8}$ the molecular features that allow nucleic acids to encode and replicate genetic information are still not available in any other material. In duplex-forming synthetic systems, the recognition sites are usually integrated into the backbone, which means that sequence variation is difficult to introduce without disrupting the complex. Synthetic oligomers that fold into well-defined secondary structures, i.e., foldamers, have also been widely studied, leading to synthetic receptors, nanomachines, and modulators of protein-protein interactions. ${ }^{9}$ Huc has shown that it is possible to program the recognition properties of foldamers by changing the sequence of building blocks. ${ }^{10}$

We recently reported a new class of synthetic molecules that form stable duplexes via multiple cooperative H-bonding interactions between recognition units appended to oligomeric backbones. ${ }^{11}$ Figure 1 shows the systems reported to date. Four different backbones have been prepared using either reductive amination or photochemical thiol-ene coupling. We found that variations in the structure of the backbone were well-tolerated, and different backbones and recognition modules could be used interchangeably to form stable duplexes. However, all of these systems are homo-sequence oligomers, i.e., all H-bond donor (D) oligomers that form duplexes with length complementary all H-bond acceptor (A) oligomers. As a first step toward mixed-sequence oligomers, in this paper we describe the properties of several $\mathrm{AD} 2$-mers based on the motifs shown in Figure 1.

Mixed-sequence oligomers introduce the possibility of intramolecular H-bonds, which can lead to folding equilibria that compete with duplex formation (Figure 2). If two

Received: February 10, 2017

Published: May 4, 2017 

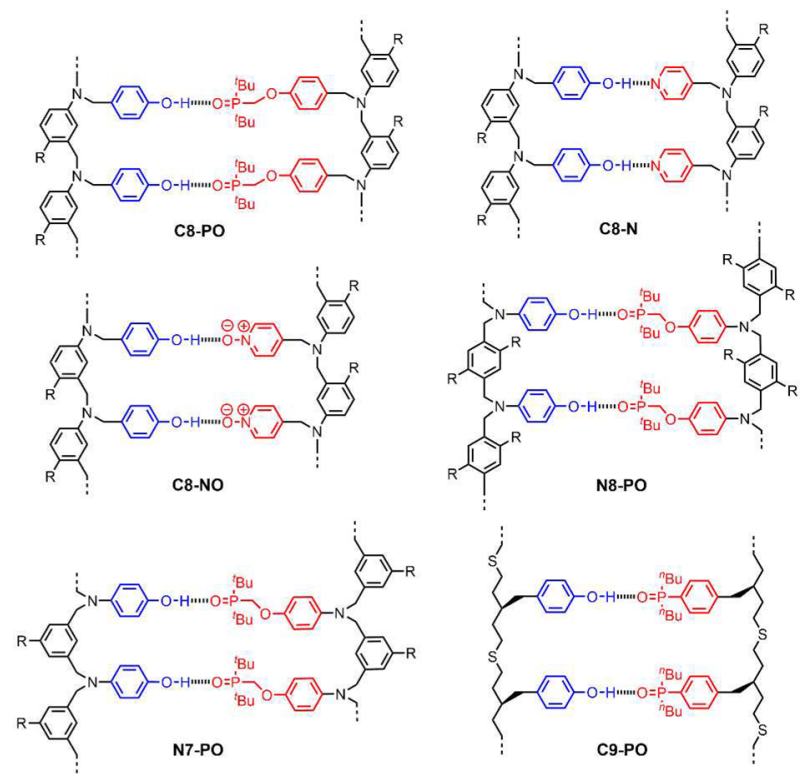

Figure 1. H-bonded duplexes formed by oligomers with different recognition units and backbones ( $\mathrm{R}$ is a solubilizing group). ${ }^{11}$ The oligomers are labeled according the type of recognition unit ( phosphine oxide $=\mathrm{PO}$, pyridine $=\mathrm{N}$, pyridine $N$-oxide $=\mathrm{NO})$, the site of attachment of the recognition units $(\mathrm{C}$ or $\mathrm{N})$, and the number of atoms separating neighboring recognition units $(7,8$, or 9$)$.

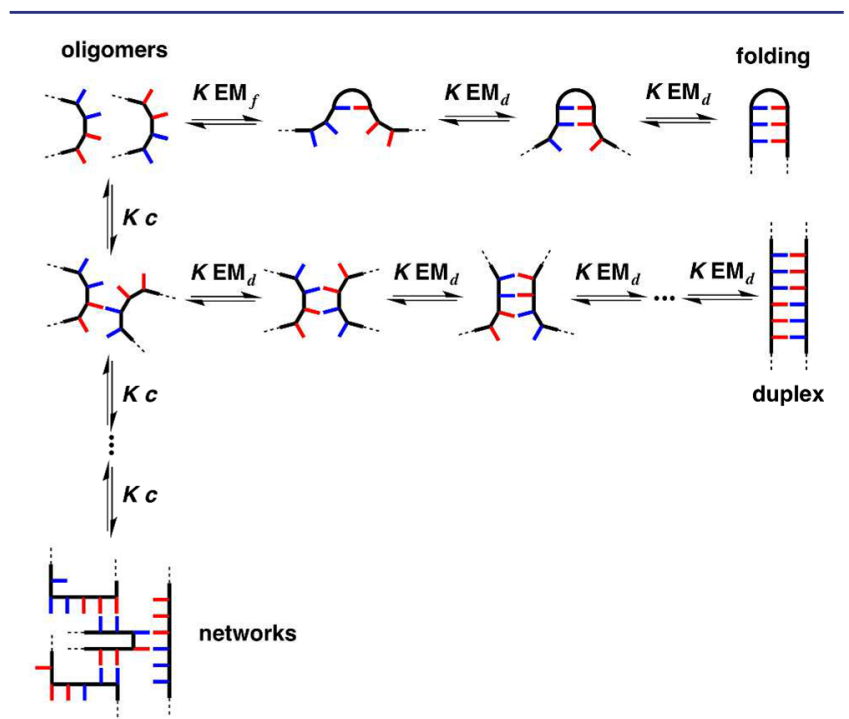

Figure 2. Competing equilibria in the formation of a duplex between two complementary oligomers. Intramolecular interactions between recognition sites lead to folding, and intermolecular interactions between multiple oligomers lead to networks of supramolecular aggregates. The effective molarities for folding $\left(\mathrm{EM}_{f}\right)$ and duplex formation $\left(\mathrm{EM}_{d}\right)$, the operating concentration $(c)$, and the association constant for formation of a $\mathrm{H}$-bond between two recognition sites $(K)$ determine the distribution of oligomers between the three different assembly channels. The equilibrium constants have additional statistical factors that are not shown.

neighboring recognition units on an oligomer interact strongly, the folding channel will be favored over the duplex assembly channel. Thus, the selectivity of mixed-sequence duplex formation is limited by the extent to which intramolecular folding occurs in $\mathrm{AD} 2$-mers. The key parameters that determine the distribution of the different species shown in
Figure 2 are the effective molarities for folding $\left(\mathrm{EM}_{f}\right)$ and duplex formation $\left(\mathrm{EM}_{d}\right)$, the operating concentration $(c)$, and the association constant for the intermolecular interaction between two complementary $\mathrm{H}$-bonding sites $(K)$. Figure 2 shows pathways where the first $\mathrm{H}$-bond formed can be intramolecular or intermolecular: if $\mathrm{EM}_{f}>c$ and $\mathrm{KEM}_{f}>1$, then the folding channel will be preferred over intermolecular interactions. If the first $\mathrm{H}$-bond formed is intramolecular, then further intramolecular interactions leading to folded hairpin loop structures will take place if the sequence is suitable and if $\mathrm{KEM}_{d}>1$. If the first $\mathrm{H}$-bond formed is intermolecular, there are two pathways for subsequent interactions: intramolecular interactions leading to duplex formation, or intermolecular interactions leading to aggregates. The duplex channel will be preferred over aggregation if $\mathrm{EM}_{d}>c$ and $\mathrm{KEM}_{d}>1$. Therefore, duplex formation will be the preferred self-assembly process if $\mathrm{EM}_{d}$ is greater than all of $c, 1 / K$, and $\mathrm{EM}_{f}$.

Before we embark on the synthesis of mixed-sequence oligomers, it is therefore important to investigate how $K, \mathrm{EM}_{d}$ and $\mathrm{EM}_{f}$ vary with the chemical structures of the monomer units. The association constant for intermolecular H-bond formation $(K)$ is straightforward to predict for any choice of recognition unit, ${ }^{12}$ but we do not yet have reliable methods for predicting effective molarities for intramolecular interactions. ${ }^{13-19}$ Here, we analyze the competing equilibria between folding and duplex formation for the seven different $\mathrm{AD}$ 2-mers shown in Figure 3. These compounds represent the six systems

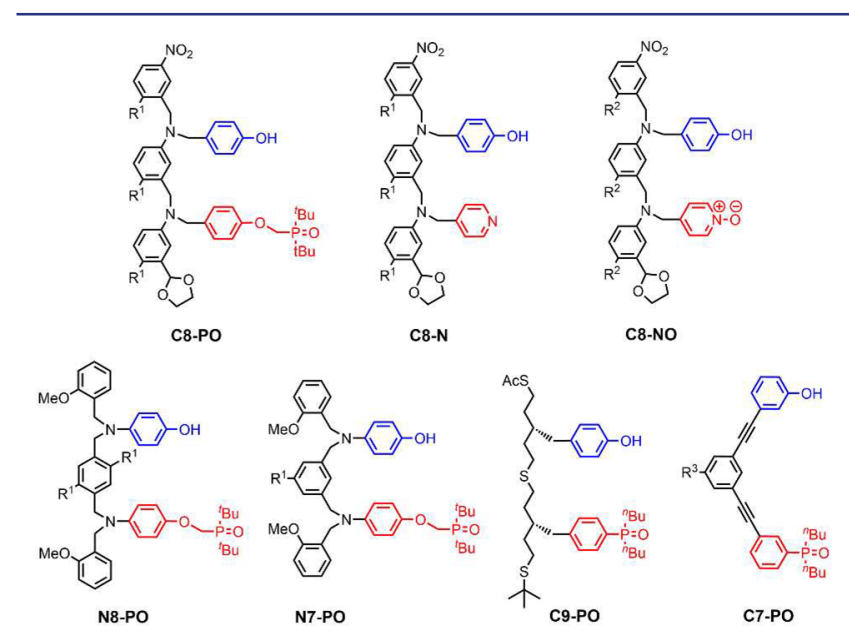

Figure 3. Chemical structures of the $A D$ 2-mers $\left(R^{1}=(2\right.$ ethylhexyl)oxy; $\mathrm{R}^{2}=\left(2\right.$-ethylhexyl)oxy or methoxy; $\mathrm{R}^{3}=\mathrm{H}$ or $S-\beta$ citronelloxy).

shown in Figure 1 for which the corresponding A.D and AA. DD complexes have been characterized previously and one additional system with a more rigid backbone (C7-PO), which provides a reference compound that cannot fold. The aim is to obtain experimental data for understanding the complex equilibria shown in Figure 2 in order to select suitable architectures for the development of mixed-sequence duplexforming oligomers.

\section{RESULTS AND DISCUSSION}

Synthesis. Two versions of the C8-NO AD 2-mer were prepared: one with (2-ethylhexyl)oxy solubilizing groups for binding studies, and one with methoxy groups for X-ray crystallography. Building blocks 4 and 7 required for synthesis of the methoxy analogue were prepared from 5-hydroxy-2- 
nitrobenzaldehyde $\mathbf{1}$ as shown in Scheme 1. After methylation of $\mathbf{1}$, the acetal-protected aldehyde $\mathbf{2}$ was obtained using

Scheme 1. Synthesis of Building Blocks 4 and 7

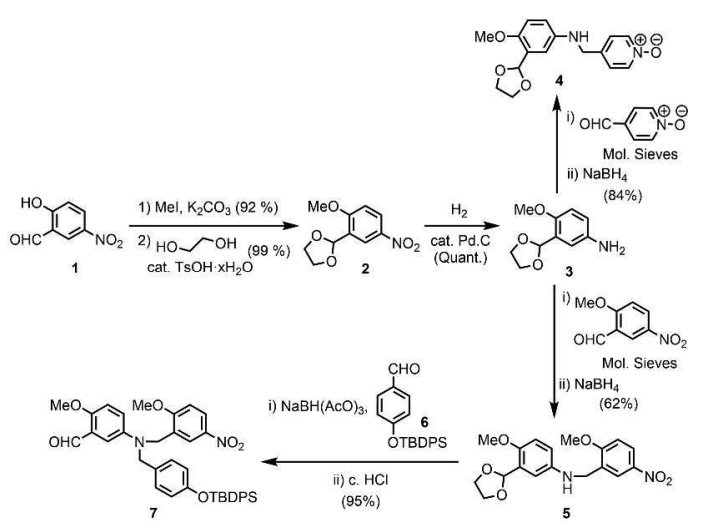

ethylene glycol and catalytic tosic acid. Hydrogenation of the nitro group yielded aniline 3 . The imines of 3 formed with $4-$ pyridinecarboxaldehyde $\mathrm{N}$-oxide or 2-methoxy-5-nitrobenzaldehyde were reduced to give 4 and 5 , respectively. Reduction of the imine derived from $\mathbf{5}$ and $\mathbf{6},{ }^{11 \mathrm{~d}}$ followed by acid removal of the acetal protecting group, gave 7 . The syntheses of the analogues of 4 and 7 bearing (2-ethylhexyl)oxy solubilizing groups instead of methoxy groups (8 and 9) were reported previously. ${ }^{11 a, c}$ Reductive amination was used to couple the phenol and $N$-oxide building blocks in good yield to give $\mathbf{1 0}$ and 11 (Scheme 2). TBAF-mediated deprotection of the phenol groups afforded the C8-NO AD 2-mers 12 and 13.

Scheme 2. Synthesis of C8-NO AD 2-mers

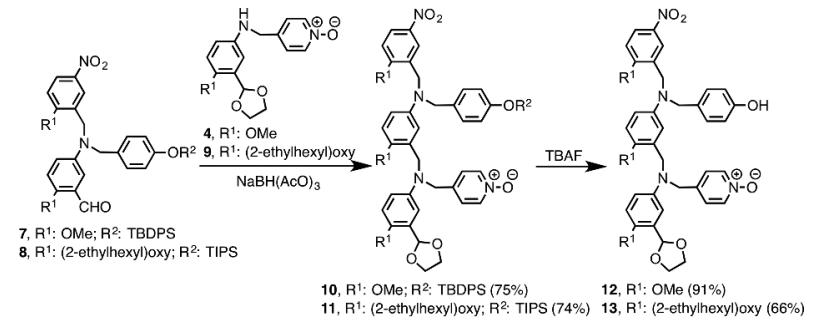

The synthesis of the C8-PO 2-mer 16 is shown in Scheme 3. Reductive amination of aldehyde 8 with aniline $14^{11 a}$ yielded 15, and deprotection using TBAF gave the $\mathrm{AD} 2$-mer 16. The route to the C8-N 2-mer 21 involves previously reported compounds 17, 18, and 20 (Scheme 4). ${ }^{1 \mathrm{a}, \mathrm{c}}$ TBAF-mediated phenol deprotection of 17 , followed by reductive amination

Scheme 3. Synthesis of C8-PO AD 2-mer ( $R=$ (2Ethylhexyl)oxy)

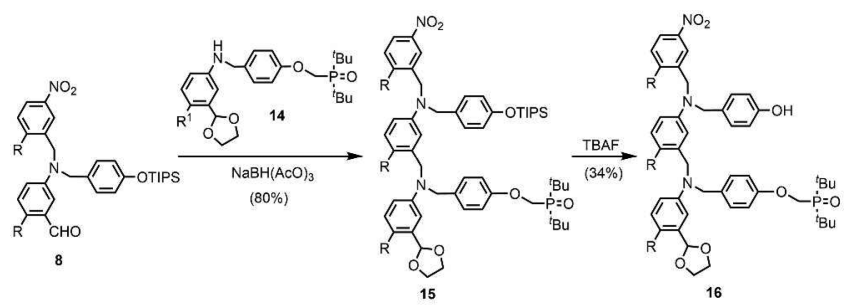

Scheme 4. Synthesis of C8-N AD 2-mer ( $R=(2-$ Ethylhexyl)oxy)

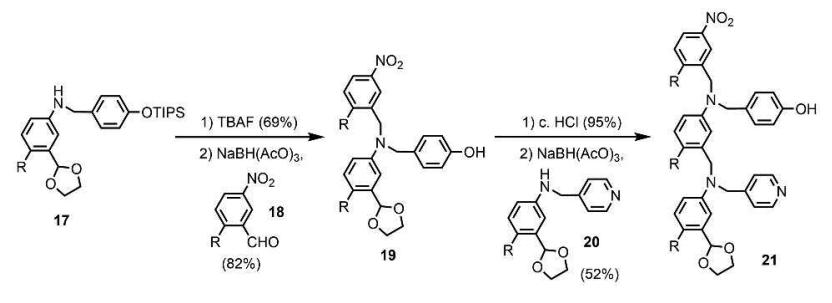

with 18, afforded 19 in good yield. After the removal of the acetal protecting group, reductive amination with $\mathbf{2 0}$ gave $\mathbf{2 1}$.

Scheme 5 shows the synthesis of the N8-PO 2-mer 26 from p-aminophenol and compounds 23 and 24, which have been

Scheme 5. Synthesis of N8-PO AD 2-mer $(R=(2-$ Ethylhexyl)oxy)

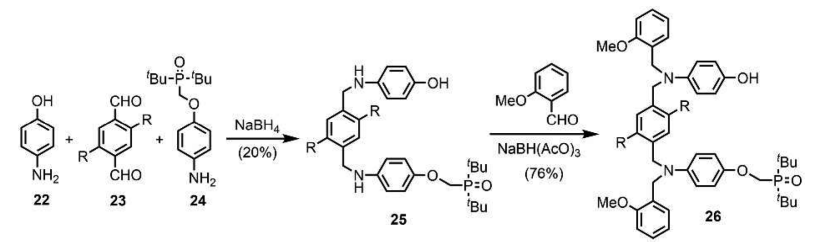

reported previously. ${ }^{11 \mathrm{~b}}$ The statistical reaction between these three components gave $\mathbf{2 5}$ in modest yield after column chromatography. The $\mathrm{NH} \mathrm{H}$-bond donor sites of 25 could potentially compete with the phenol recognition units, so they were removed by capping with 2-methoxybenzaldehyde to give 26.

The N7-PO AD 2-mer 29 differs from the N8-PO AD 2-mer 26 in the position of the substituents on the backbone aromatic ring. 29 was obtained using a synthetic strategy similar to that used for 26 but with the isophthalaldehyde derivative 27 in place of $\mathbf{2 3}$ (Scheme 6). ${ }^{11 \mathrm{~b}}$ The statistical reaction of $\mathbf{2 7}$ with 22 and 24 yielded 28 after column chromatography, and subsequent reductive amination with 2-methoxybenzaldehyde gave 29.

Scheme 6. Synthesis of N7-PO AD 2-mer $(R=(2-$ Ethylhexyl)oxy)

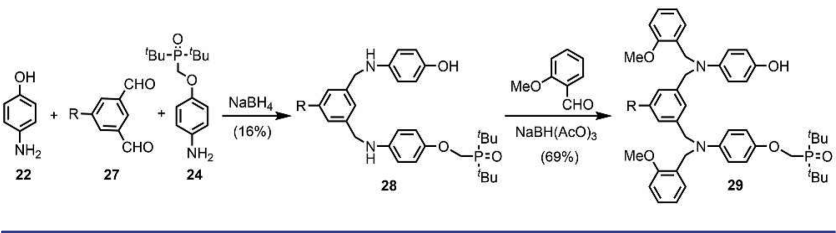

Photochemically initiated thiol-ene coupling was used to synthesize the C9-PO 2-mer 33 from 30 and 32 (Scheme 7). ${ }^{11}$ Thiol-ene-mediated capping of $\mathbf{3 0}$ with tert-butyl mercaptan gave 31. Removal of the $S$-acetyl protecting group of 31 under

Scheme 7. Synthesis of C9-PO AD 2-mer

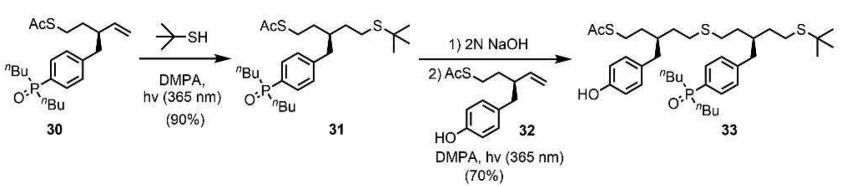


basic conditions, and subsequent thiol-ene coupling with 32, afforded 33 in good yield.

The C7-PO AD 2-mer is a new backbone architecture, so the corresponding AA and DD 2-mers were also synthesized. The AA.DD complex provides an important reference point for characterizing duplex formation (see Supporting Information for the synthesis of the corresponding A and D 1-mers). The C7-PO compounds were all prepared using Sonogashira coupling. The required phosphine oxide building blocks 35 and 36 were prepared as shown in Scheme 8. Palladium-

Scheme 8. Synthesis of Building Blocks 35 and 36

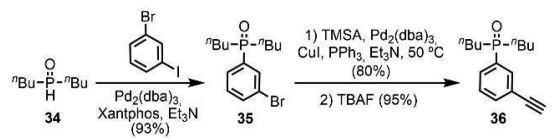

mediated P-arylation of 3-bromoiodobenzene with di- $n$-butylphosphine $34^{11 \mathrm{~d}}$ gave 35 in excellent yield. Sonogashira coupling with trimethylsilylacetylene (TMSA) followed by TBAF-mediated deprotection gave 36. Scheme 9 shows the

Scheme 9. Synthesis of C7-PO AA and DD 2-mers $(\mathrm{R}=S-\beta$ Citronelloxy)

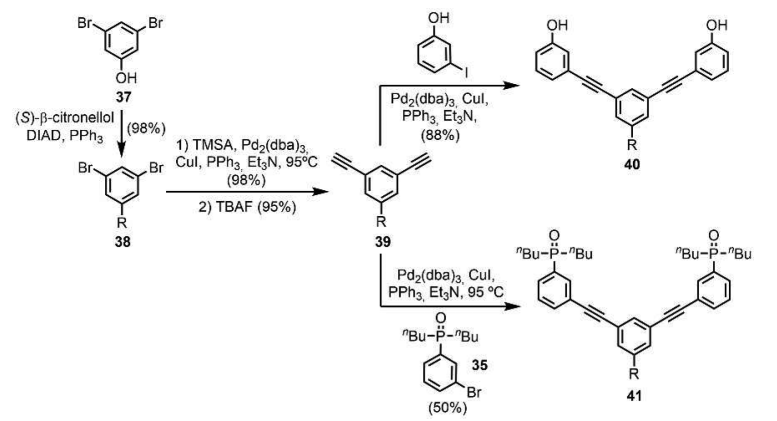

synthesis of the C7-PO AA 2-mer (40) and the C7-PO DD 2mer (41). A Mitsunobu reaction between 3,5-dibromophenol and $S$ - $(-)-\beta$-citronellol yielded 38 in excellent yield. A double Sonogashira coupling with TMSA followed by alkyne deprotection gave 39. Double Sonogashira coupling of 39 with 3-iodophenol or $\mathbf{3 5}$ gave $\mathbf{4 0}$ and $\mathbf{4 1}$.

Two versions of the C7-PO AD 2-mer were prepared: one with a $(S)-\beta$-citronelloxy solubilizing group for binding studies (44), and one with no solubilizing groups for X-ray crystallography (47). The C7-PO AD 2-mer (44) was synthesized from compound $\mathbf{3 8}$ in three steps (Scheme 10).

Scheme 10. Synthesis of C7-PO AD 2-mer for Binding Studies $(\mathrm{R}=\boldsymbol{S}$ - $\boldsymbol{\beta}$-Citronelloxy $)$

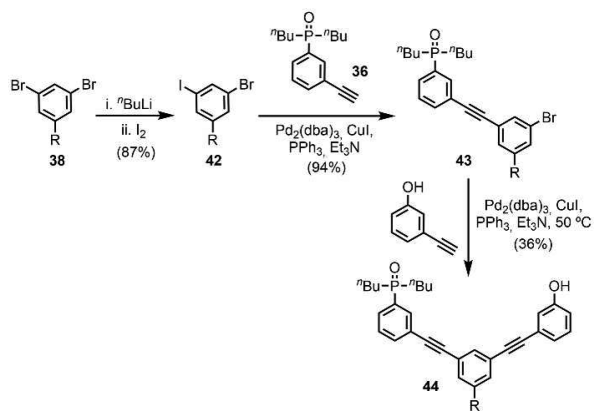

Lithium-halogen exchange using $n$-BuLi followed by reaction with iodine gave the bromoiodobenzene derivative $\mathbf{4 2}$ in good yield. A selective Sonogashira coupling between the iodide substituent and alkyne 36 gave 43 in excellent yield, and subsequent Sonogashira coupling between the bromine substituent and 3-hydroxyphenylacetylene gave 44. The C7$\mathrm{PO} \mathrm{AD}$ 2-mer 47, which does not have the solubilizing group, was prepared from a statistical Sonogashira coupling of an equimolar mixture of 36,45 , and 46 followed by column chromatography (Scheme 11).

\section{Scheme 11. Synthesis of C7-PO AD 2-mer for X-ray} Crystallography

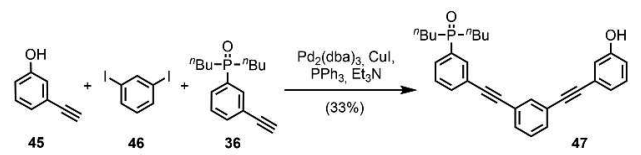

NMR Binding Studies. NMR titration and dilution experiments were performed to measure the association constants for the A.D, AA.DD, and $\mathrm{AD} \cdot \mathrm{AD}$ complexes (Table 1). For the A.D and AA.DD complexes, association constants were determined by fitting ${ }^{1} \mathrm{H}$ and ${ }^{31} \mathrm{P}$ NMR titration data to a 1:1 binding isotherm. ${ }^{11}$ Self-association constants for the $\mathrm{AD} \cdot \mathrm{AD}$ complexes were determined by fitting ${ }^{1} \mathrm{H}$ and ${ }^{31} \mathrm{P}$ NMR dilution data to a dimerization isotherm.

Figure 4 shows the equilibria that are possible in these systems. Under dilute conditions, the higher order complexes are not expected to be significantly populated. The equilibrium constants for the A.D complexes measure the intrinsic H-bond strength of the recognition units $(K)$, which is similar for the phenol-phosphine oxide and phenol- $\mathrm{N}$-oxide systems and an order of magnitude lower for the phenol-pyridine system. The phenol-phosphine oxide recognition system was also studied in chloroform, where the association constant is an order of magnitude lower than in toluene (see C7-PO entry in Table 1). For the AA.DD complexes, the product $\mathrm{KEM}_{d}$ is greater than 1 in all cases, which means that the duplex shown in Figure $4 \mathrm{a}$ is the most populated state for concentrations lower than $\mathrm{EM}_{d}$. The values of $K_{\text {duplex }}$ in Figure 4 are expected to be similar for the $\mathrm{AA} \cdot \mathrm{DD}$ and corresponding $\mathrm{AD} \cdot \mathrm{AD}$ duplexes. If there were no competing equilibria, then the observed self-association constants for the $\mathrm{AD}$ systems would be similar to the association constants measured for formation of the corresponding AA.DD duplexes. For most of the systems in Table 1, this is not the case, which means that the competing equilibria shown in Figure $4 \mathrm{~b}$ play an important role in the selfassociation of the $\mathrm{AD} 2$-mers.

Figure 4 shows that the equilibria involving the partially bound 1:1 complex and the closed duplex are the same for the $\mathrm{AA} \cdot \mathrm{DD}$ and $\mathrm{AD} \cdot \mathrm{AD}$ systems, so we assume that the relative populations of these states are similar in both cases; i.e., the closed duplex dominates. The major competing equilibrium that leads to the lower self-association constants observed for the $\mathrm{AD}$ systems must therefore be due to folding of the monomer to form an intramolecular A.D H-bond. This conclusion is supported by examination of the ${ }^{31} \mathrm{P}$ NMR chemical shifts of the free $\left(\delta_{\text {free }}\right)$ and bound $\left(\delta_{\text {bound }}\right)$ states from the dilution experiments (Table 2). With the exception of the C7-PO system, the free chemical shifts for the AD 2-mers are much higher than the values observed for the corresponding A 1-mers and AA 2-mers. The free chemical shift measured in the 
Table 1. Association Constants $\left(K_{\mathrm{obs}}\right)$ and Effective Molarities (EM) Measured by NMR Titrations and Dilutions in Toluene- $d_{8}$ at $298 \mathrm{~K}^{a}$

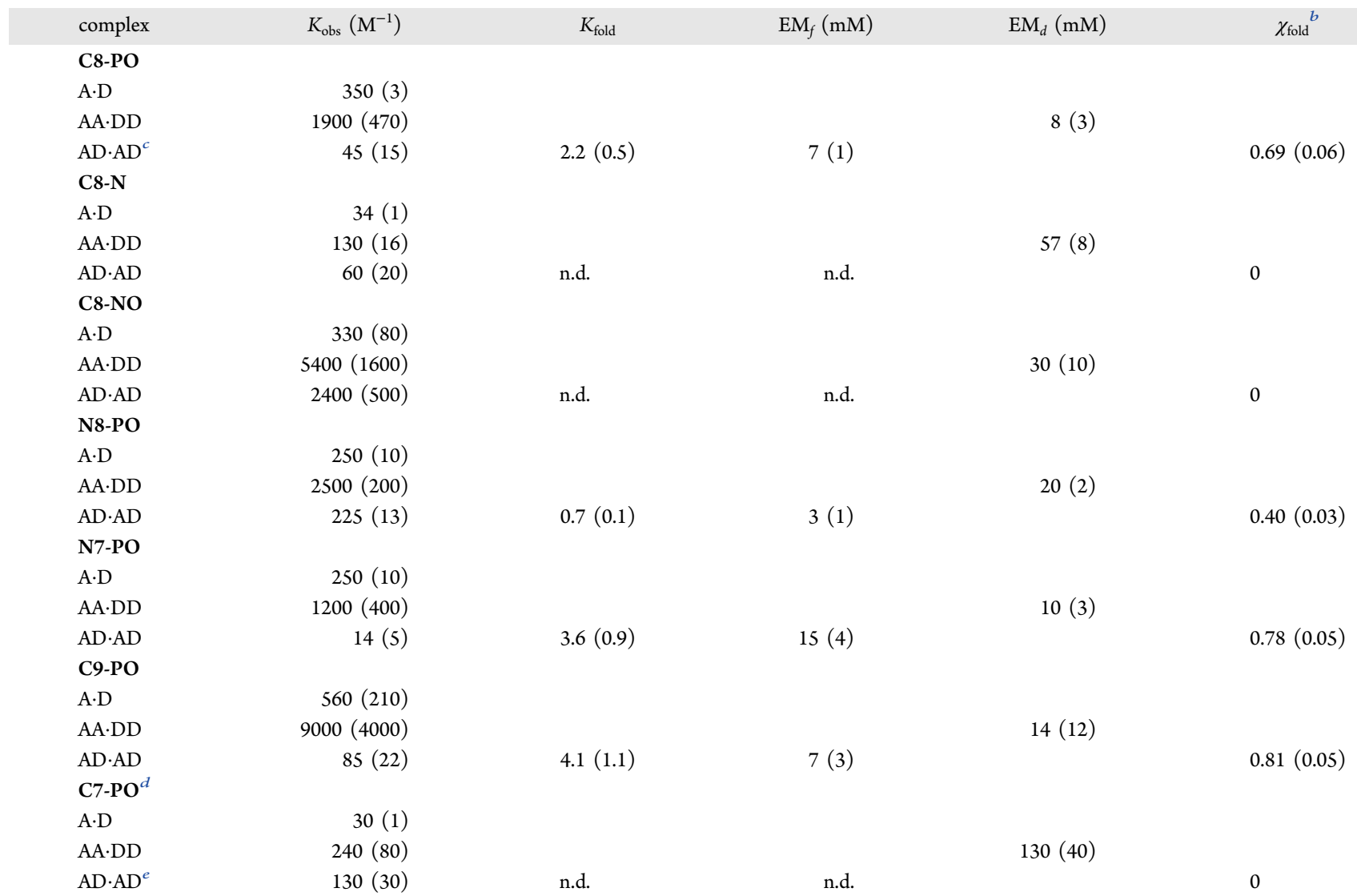

${ }^{a}$ Average values with errors (reported in parentheses) at the $95 \%$ confidence limit based on the variation between different signals and experiments. ${ }^{b}$ Calculated from $K_{\text {fold }}$ using eq $8 .{ }^{c} \mathrm{AD} 2$-mer 16. ${ }^{d}$ Experiments carried out in $\mathrm{CDCl}_{3}$ due to the high stability of the complexes in toluene- $d_{8}$. ${ }^{e} \mathrm{AD} 2$ mer 44. n.d. = not detected.

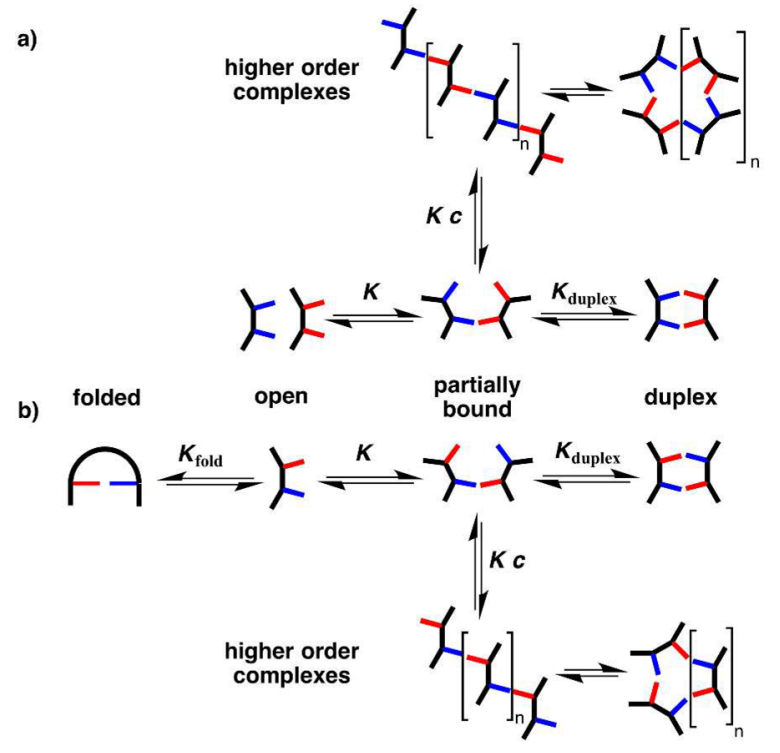

Figure 4. Competing equilibria in the assembly of (a) AA.DD and (b) $\mathrm{AD} \cdot \mathrm{AD}$ duplexes. The equilibrium constants have additional statistical factors that are not shown.

$\mathrm{AD}$ dilution experiments is the population-weighted average over all monomeric states, so the higher values of $\delta_{\text {free }}$ observed for the $\mathrm{AD} 2$-mers indicate that the folded state with an intramolecular $\mathrm{H}$-bond is significantly populated.

The data in Tables 1 and 2 can used to determine the equilibrium constant for folding, $K_{\text {fold, }}$ in these systems. Equations 1-3 show the relationship between the measured self-association constant for dimerization of $\mathrm{AD} \cdot \mathrm{AD}, K_{\mathrm{obs}}$, and the equilibrium constants, $K_{\text {duplex }}$ and $K_{\text {fold }}$, illustrated in Figure $4 \mathrm{~b}$.

$$
K_{\mathrm{obs}}=\frac{[\mathrm{AD} \cdot \mathrm{AD}]}{[\mathrm{AD}]^{2}}
$$

where $[\mathrm{AD}]$ is the total concentration of monomeric $\mathrm{AD} 2$-mer as defined in eq 2 , i.e., the sum of the open, $[\mathrm{AD}]_{\mathrm{open}}$ and folded, $[\mathrm{AD}]_{\text {fold }}$, states.

$$
[\mathrm{AD}]=[\mathrm{AD}]_{\mathrm{open}}+[\mathrm{AD}]_{\mathrm{fold}}=\left(1+K_{\mathrm{fold}}\right)[\mathrm{AD}]_{\mathrm{open}}
$$

Combining eqs 1 and 2 allows $K_{\text {obs }}$ to be expressed as a function of $K_{\text {fold }}$ and $K_{\text {duplex }}$ the equilibrium constant for the formation of the $\mathrm{AD} \cdot \mathrm{AD}$ duplex from the open monomeric state (eq 3).

$$
K_{\mathrm{obs}}=\frac{[\mathrm{AD} \cdot \mathrm{AD}]}{[\mathrm{AD}]_{\text {open }}^{2}} \frac{1}{\left(1+K_{\text {fold }}\right)^{2}}=\frac{K_{\text {duplex }}}{\left(1+K_{\text {fold }}\right)^{2}}
$$

Rearranging eq 3 allows $K_{\text {fold }}$ to be expressed in terms of $K_{\text {obs }}$ and $K_{\text {duplex }}($ eq 4$)$. 


$$
K_{\text {fold }}=\sqrt{\frac{K_{\text {duplex }}}{K_{\text {obs }}}}-1
$$

If we assume that the $\mathrm{AD} \cdot \mathrm{AD}$ and $\mathrm{AA} \cdot \mathrm{DD}$ duplexes make $\mathrm{H}$ bonds of similar stability, then it is possible to use the equilibrium constant for formation of the AA.DD duplex to estimate $K_{\text {duplex }}$. In systems where multiple H-bonding sites are constrained in very close proximity, local secondary electrostatic interactions can alter the relative stabilities of different $\mathrm{H}$ bonding patterns, but the recognition sites in the compounds described here are too far apart for such effects to be significant. ${ }^{18}$ However, there is a difference in symmetry between the $\mathrm{AA} \cdot \mathrm{DD}$ and $\mathrm{AD} \cdot \mathrm{AD}$ duplexes, which leads to a statistical contribution to the value of $K_{\text {duplex }}$. For AA.DD, there is one unbound state, but there are two degenerate states for the duplex, because two different $\mathrm{H}$-bonding arrangements are possible. ${ }^{19}$ The $\mathrm{AD} \cdot \mathrm{AD}$ duplex is made from two identical molecules, so there are two degenerate unbound states, but there is one bound state, because only one H-bonding arrangement is possible. Thus, the observed association constant for formation of the AA.DD duplex, $K_{\text {obs }}(\mathrm{AA} \cdot \mathrm{DD})$, can be used to estimate $K_{\text {duplex }}$ for formation of the $\mathrm{AD} \cdot \mathrm{AD}$ duplex from the open monomeric state (eq 5), and the resulting values were used in eq 4 to calculate values of $K_{\text {fold }}$.

$$
K_{\text {duplex }} \approx 0.25 K_{\text {obs }}(\mathrm{AA} \cdot \mathrm{DD})
$$

The effective molarity for intramolecular H-bonding in the monomeric state, $\mathrm{EM}_{f}$, is given by the ratio of $K_{\text {fold }}$ to the association constant for the corresponding intermolecular interaction, $K_{\mathrm{A} \cdot \mathrm{D}}$ (eq 6).

$$
\mathrm{EM}_{f}=\frac{K_{\text {fold }}}{K_{\mathrm{A} \cdot \mathrm{D}}}
$$

The values of $K_{\text {fold }}$ can also be used to estimate the relative populations of the open $\left(\chi_{\text {open }}\right)$ and folded states $\left(\chi_{\text {fold }}\right)$ for the monomeric $\mathrm{AD} 2$-mers (eq 7).

$$
\chi_{\text {fold }}+\chi_{\text {open }}=\left(1+K_{\text {fold }}\right)\left(1+\chi_{\text {fold }}\right)=1
$$

Rearranging eq 7 allows $\chi_{\text {fold }}$ to be calculated from the value of $K_{\text {fold }}$ (eq 8).

$$
\chi_{\mathrm{fold}}=1-\frac{1}{\left(1+K_{\mathrm{fold}}\right)}
$$

The values of $K_{\text {fold }}, \mathrm{EM}_{f}$, and $\chi_{\text {fold }}$ are tabulated in Table 1 for each of the seven $\mathrm{AD} 2$-mers. Four systems fold to a significant extent, and the other three systems show no evidence of folding. No folding was observed for C7-PO, which has a rigid backbone that holds the recognition sites apart. The other two systems that do not fold are $\mathrm{C} 8 \mathrm{-N}$ and $\mathrm{C} 8 \mathrm{-NO}$, which have a relatively flexible backbone. A common feature of the three $\mathrm{AD}$ 2 -mers that do not fold is that the recognition units are connected by fewer than five rotatable bonds. Although C8-PO shares the same backbone as $\mathrm{C} 8-\mathrm{N}$ and $\mathrm{C} 8 \mathrm{-NO}$, this system does fold due to the additional flexibility associated with the two atom linker that connects the phosphine oxide to the aromatic ring. For C8-PO, C9-PO, and N7-PO, the folded state is highly populated $\left(\chi_{\mathrm{fold}}=70-80 \%\right)$. N8-PO also folds, but the effective molarity for folding $\left(\mathrm{EM}_{\mathrm{f}}\right)$ is lower, so the open and folded states are equally populated $\left(\chi_{\text {fold }} \approx 40 \%\right)$. The values of $\mathrm{EM}_{f}$ and $\mathrm{EM}_{d}$ are similar in all four cases and fall in the range
3-20 mM. For the systems that do not fold, the values of $\mathrm{EM}_{d}$ are somewhat higher $(30-130 \mathrm{mM})$.

The ${ }^{31} \mathrm{P}$ NMR chemical shift data in Table 2 can also be used to estimate values of $\chi_{\text {fold }}$. The values of $\delta_{\text {bound }}$ for the A.D, AA. $\mathrm{DD}$, and $\mathrm{AD} \cdot \mathrm{AD}$ complexes are similar in all cases, indicating that the phosphine oxides are fully $\mathrm{H}$-bonded. However, there are significant differences between the values of $\delta_{\text {free }}$ for the $\mathrm{AD}$. $\mathrm{AD}$ complexes compared with the corresponding $\mathrm{A} \cdot \mathrm{D}$ and $\mathrm{AA}$. DD complexes, because the values represent the populationweighted average of the chemical shifts of the open and folded states of the $\mathrm{AD}$ monomer. If we assume that the open $\mathrm{AD}$ monomer has the same chemical shift as the free state of $\mathrm{A}\left(\delta_{\mathrm{A}}\right)$ and that the folded $\mathrm{AD}$ monomer has the same chemical shift as the bound state A.D $\left(\delta_{\mathrm{A} \cdot \mathrm{D}}\right)$, the free chemical shift observed for the $\mathrm{AD} 2$-mer $\left(\delta_{\text {free }}\right)$ can be used to quantify the population of the folded state via eq 9.

$$
\delta_{\text {free }}=\chi_{\text {fold }} \delta_{\mathrm{A} \cdot \mathrm{D}}+\chi_{\text {open }} \delta_{\mathrm{A}}
$$

The limiting complexation-induced change in chemical shift observed in dilution experiments for the $\mathrm{AD} 2$-mers $\left(\Delta \delta_{\mathrm{AD} \cdot \mathrm{AD}}\right)$ can be expressed as eq 10 .

$$
\delta_{\mathrm{AD} \cdot \mathrm{AD}}=\delta_{\text {free }}-\delta_{\text {bound }}=\left(1-\chi_{\text {fold }}\right)\left(\delta_{\mathrm{A}}-\delta_{\mathrm{A} \cdot \mathrm{D}}\right)
$$

Rearranging eq 10 allows $\chi_{\text {fold }}$ to be obtained from the values of $\Delta \delta_{\mathrm{AD} \cdot \mathrm{AD}}$ and $\Delta \delta_{\mathrm{A} \cdot \mathrm{D}}\left(\right.$ or $\Delta \delta_{\mathrm{AA} \cdot \mathrm{DD}}$ ) listed in Table 2 (eq 11).

$$
\chi_{\mathrm{fold}}=1-\frac{\Delta \delta_{\mathrm{AD} \cdot \mathrm{AD}}}{\Delta \delta_{\mathrm{A} \cdot \mathrm{D}}}=1-\frac{\Delta \delta_{\mathrm{AD} \cdot \mathrm{AD}}}{\Delta \delta_{\mathrm{AA} \cdot \mathrm{DD}}}
$$

\begin{tabular}{|c|c|c|c|c|}
\hline complex & $\delta_{\text {free }}$ & $\delta_{\text {bound }}$ & $\Delta \delta$ & $\chi_{\text {fold }}{ }^{a}$ \\
\hline \multicolumn{5}{|l|}{ C8-PO } \\
\hline$A \cdot D$ & 53.7 & 58.7 & 5.0 & \\
\hline $\mathrm{AA} \cdot \mathrm{DD}$ & 53.6 & 58.8 & 5.2 & \\
\hline $\mathrm{AD} \cdot \mathrm{AD}^{b}$ & 57.0 & 58.1 & 1.1 & $0.78(0.01)$ \\
\hline \multicolumn{5}{|l|}{ N8-PO } \\
\hline$A \cdot D$ & 53.5 & 58.5 & 5.0 & \\
\hline $\mathrm{AA} \cdot \mathrm{DD}$ & 53.5 & 57.5 & 4.0 & \\
\hline $\mathrm{AD} \cdot \mathrm{AD}$ & 55.1 & 57.5 & 2.4 & $0.46(0.08)$ \\
\hline \multicolumn{5}{|l|}{ N7-PO } \\
\hline$A \cdot D$ & 53.5 & 58.5 & 5.0 & \\
\hline $\mathrm{AA} \cdot \mathrm{DD}$ & 53.4 & 60.3 & 6.9 & \\
\hline $\mathrm{AD} \cdot \mathrm{AD}$ & 56.5 & 57.9 & 1.4 & $0.76(0.05)$ \\
\hline \multicolumn{5}{|l|}{ C9-PO } \\
\hline$A \cdot D$ & 35.4 & 41.8 & 6.4 & \\
\hline $\mathrm{AA} \cdot \mathrm{DD}$ & 35.6 & 42.0 & 6.4 & \\
\hline $\mathrm{AD} \cdot \mathrm{AD}$ & 40.6 & 41.1 & 0.5 & $0.92(0.01)$ \\
\hline \multicolumn{5}{|l|}{$\mathrm{C}^{7-\mathbf{P O}^{c}}$} \\
\hline$A \cdot D$ & 40.3 & 45.8 & 5.5 & \\
\hline $\mathrm{AA} \cdot \mathrm{DD}$ & 40.2 & 44.4 & 4.2 & \\
\hline $\mathrm{AD} \cdot \mathrm{AD}^{d}$ & 40.2 & 44.1 & 3.9 & $0.18(0.16)$ \\
\hline
\end{tabular}

Figure 5 shows that there is a good correlation between the values of $\chi_{\text {fold }}$ calculated from the association constants (eq 8) and those obtained from the complexation-induced changes in ${ }^{31}$ P NMR chemical shift (eq 11). For systems with phosphine oxide H-bond acceptors, the ${ }^{31} \mathrm{P}$ NMR chemical shift therefore

Table 2. ${ }^{31} \mathrm{P}$ NMR Chemical Shifts (ppm) Measured in Toluene- $d_{8}$ at $298 \mathrm{~K}$

${ }^{a}$ Average value and standard deviation (reported in parentheses) calculated from $\Delta \delta_{\mathrm{A} \cdot \mathrm{D}}$ and $\Delta \delta_{\mathrm{AA} \cdot \mathrm{DD}}$ using eq $11 .{ }^{b} \mathrm{AD}$ 2-mer 16. ${ }^{c}$ Experiments carried out in $\mathrm{CDCl}_{3}$ due to the high stability of the complexes in toluene- $d_{8}$. ${ }^{d} \mathrm{AD} 2$-mer 44. 


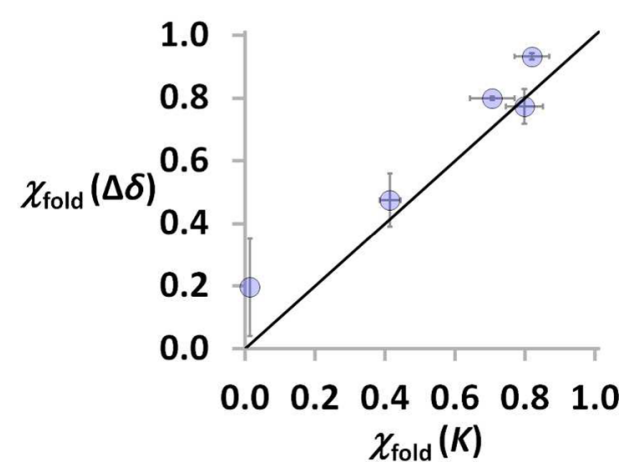

Figure 5. Correlation between $\chi_{\text {fold }}$ estimated using changes in chemical shift $(\Delta \delta$, eq 11) and association constants $(K$, eq 8$)$. The line corresponds to $y=x$.

provides a convenient and straightforward method for assessing folding. For systems where this chemical shift information is not available, the correlation in Figure 5 provides confidence that the method for assessing folding on the basis of measurement of association constants is robust.

Three-Dimensional Structures. Molecular mechanics calculations provide insight into the folding propensity of the $\mathrm{AD}$ 2-mers. A conformational search using the MMFFs forcefield was performed for the monomer of each of the seven $\mathrm{AD}$ 2-mers (see Supporting Information for details). A folded conformation featuring an intramolecular H-bond is the lowest energy structure for all four systems that were found to fold in the NMR experiments (Figure 6).

The global minimum for the C8-N system and for the C7PO system corresponds to an open conformation, in agreement with the experimental results. However, molecular modeling

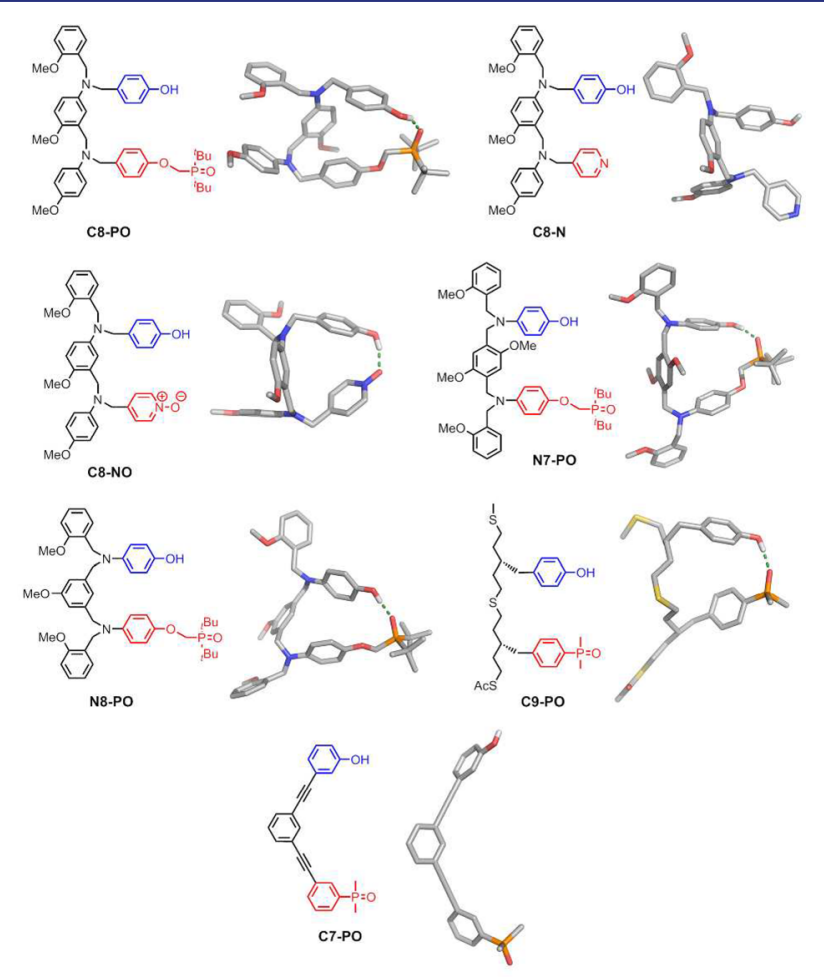

Figure 6. Lowest energy conformations of AD 2-mers calculated using molecular mechanics conformational searches (MMFFs force-field and $\mathrm{CHCl}_{3}$ solvation implemented in Macromodel). ${ }^{20}$ suggests that the $\mathrm{C} 8 \mathrm{-NO} \mathrm{AD}$ 2-mer folds with an intramolecular pyridine $\mathrm{N}$-oxide-phenol $\mathrm{H}$-bond, which contradicts the results of the NMR experiments in Table 1. Analysis of the partial atomic charges assigned by the force-field reveals that the charge on the oxygen of the pyridine $\mathrm{N}$-oxide acceptor is significantly higher than that on the oxygen of the phosphine oxide in the C8-PO AD 2-mer. The association constant for formation of a phosphine oxide-phenol H-bond in the A.D complex in Table 1 is slightly higher than the value for a pyridine $\mathrm{N}$-oxide-phenol $\mathrm{H}$-bond, ${ }^{12}$ so the folded conformation calculated for the C8-NO system may be an artifact of unrealistic partial atomic charges that overestimate the $\mathrm{H}$-bond strength.

The structures of the complexes formed by the C8-NO and C7-PO AD 2-mers were also investigated using X-ray crystallography. The X-ray crystal structure of the methoxy analogue of the C8-NO AD 2-mer (12) shows formation of the doubly H-bonded antiparallel duplex (Figure 7). Despite the

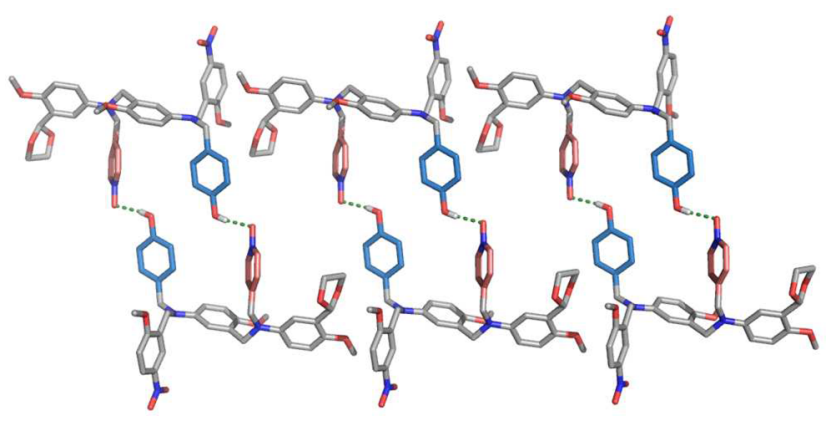

Figure 7. Single-crystal X-ray structure of $\mathbf{1 2}$, which forms a doubly $\mathrm{H}$ bonded duplex in the solid state. Three adjacent unit cells with a total of six molecules of $\mathbf{1 2}$ are shown. Hydrogen atoms have been omitted for clarity. The backbones are shown in gray, the H-bond donor recognition units in blue, and the H-bond acceptor units in red.

molecular modeling prediction of folding for this system, X-ray crystallography is consistent with the NMR result that the intermolecular channel leading to bimolecular duplexes is favored over the intramolecular channel leading to folded structures.

The X-ray crystal structure of 47, the analogue of the C7-PO $\mathrm{AD} 2$-mer with no solubilizing group, was also determined (Figure 8). There is no intramolecular folding in the solid state, in agreement with the solution-phase NMR results, but a duplex is not observed. Instead, 47 crystallizes as a linear $\mathrm{H}$ bonded polymer, the state that the $\mathrm{AD} 2$-mers are likely to populate at high concentrations $\left(c>\mathrm{EM}_{d}\right)$.

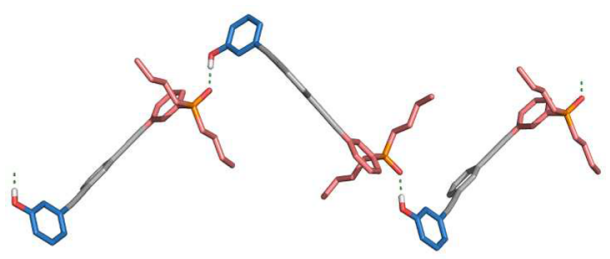

Figure 8. Single-crystal X-ray structure of 47 , which forms a linear $\mathrm{H}$ bonded polymer in the solid state. Three adjacent unit cells with a total of three molecules of $\mathbf{4 7}$ are shown. Hydrogen atoms have been omitted for clarity. The backbones are shown in gray, the H-bond donor recognition units in blue, and the $\mathrm{H}$-bond acceptor units in red. 


\section{CONCLUSIONS}

Self-complementary molecules bearing H-bond donors (D) and acceptors (A) can make either intermolecular interactions to form a duplex or intramolecular interactions to fold. A quantitative analysis of these competing equilibria is described for a family of seven different $\mathrm{AD}$ 2-mers, which represent the shortest mixed-sequence systems from a family of longer oligomers. The compounds were prepared using a variety of coupling chemistries (reductive amination, thiol-ene, and Sonogashira coupling) and differ in the flexibility and geometric complementarity of the backbone and in the nature of the $\mathrm{H}$ bond recognition units.

The equilibrium constants for intramolecular folding, $K_{\text {fold }}$ cannot be measured directly because the folded and open conformers are in fast exchange on the NMR time scale. However, it is possible to infer the value of $K_{\text {fold }}$ by comparing the equilibrium constant for self-association of an $\mathrm{AD} 2$-mer with the equilibrium constant for formation of the isomeric AA. DD duplex, where the two components cannot fold. For systems that have phosphine oxide H-bond acceptors, the accuracy of this method was confirmed by comparison of the ${ }^{31} \mathrm{P}$ NMR chemical shifts of the free and bound states. For $\mathrm{AD}$ 2-mers that fold to a significant extent, the phosphine oxide is involved in an intramolecular H-bond, so the free chemical shift for the monomeric state is very similar to the bound chemical shift for the $\mathrm{AD} \cdot \mathrm{AD}$ duplex. The free and bound chemical shifts for the $\mathrm{AD} \cdot \mathrm{AD}$ complex can be related to the corresponding values for the A.D and AA.DD complexes to quantify the populations of folded and open states in the monomeric form of $\mathrm{AD}$, and hence $K_{\text {fold }}$. The results of the chemical shift and association constant methods show good quantitative agreement.

The three key parameters that determine the behavior of these systems are the association constant for $\mathrm{H}$-bond formation between the recognition units and the effective molarities for intramolecular folding, $\mathrm{EM}_{f}$, and duplex formation, $\mathrm{EM}_{d}$. In all seven systems, $\mathrm{EM}_{d}$ is larger than $1 / K$, which means that efficient duplex formation is observed for $1: 1$ complexes of two homo-oligomers, AA.DD. In four systems, $\mathrm{EM}_{f}$ is comparable to $\mathrm{EM}_{d}$, which means that the $\mathrm{AD}$ 2-mers prefer folding over duplex formation at low concentrations. It is possible to force these systems to form $\mathrm{AD} \cdot \mathrm{AD}$ duplexes at high concentrations, but the association constants for duplex formation are 1-2 orders of magnitude lower than those observed for the isomeric AA.DD complexes. For the other three systems, $\mathrm{EM}_{f} \ll \mathrm{EM}_{d}$, and no evidence for intramolecular folding was observed. This conclusion is supported by X-ray crystal structures of two of the systems that do not fold in solution: one forms the doubly $\mathrm{H}$-bonded $\mathrm{AD} \cdot \mathrm{AD}$ duplex in the solid state, and the other forms a supramolecular polymer where the molecules are connected by single A.D H-bonding interactions.

We previously found that the value of $\mathrm{EM}_{d}$ for duplex formation does not depend greatly on the conformational flexibility of the backbone. This work shows that folding equilibria are more sensitive to the nature of the backbone. The three $\mathrm{AD}$ 2-mers that do not fold have recognition units connected by fewer than five rotatable bonds, but when the backbone is more flexible, folding is observed. This observation provides a convenient rule of thumb for the design of systems where duplex formation is favored over intramolecular folding of neighboring recognition units. In longer oligomers, the probability of folding between recognition units that are remote in sequence will increase, even for relatively rigid backbones. These more complex folding patterns are something that we hope to exploit in the development of synthetic information molecules that exhibit both sequence-selective duplex formation and sequence-directed folding properties. Work on the synthesis of longer mixed-sequence oligomers using the systems identified here that do not fold is in progress (Figure 9).

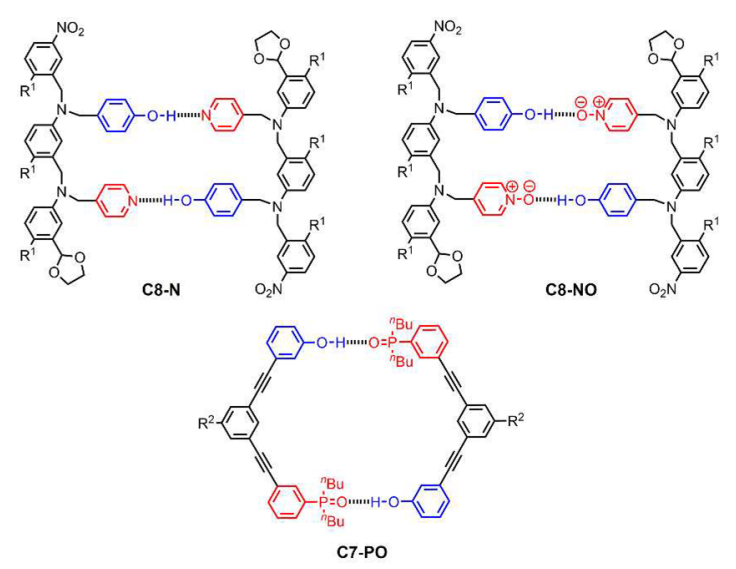

Figure 9. Structures of duplexes formed by AD 2-mers that do not fold $\left(\mathrm{R}^{1}=\right.$ (2-ethylhexyl)oxy; $\mathrm{R}^{2}=S$ - $\beta$-citronelloxy).

\section{ASSOCIATED CONTENT}

\section{S Supporting Information}

The Supporting Information is available free of charge on the ACS Publications website at DOI: $10.1021 /$ jacs.7b01357.

Detailed experimental procedures and ${ }^{1} \mathrm{H}$ and ${ }^{13} \mathrm{C}$ NMR spectra of all compounds, NMR titration and dilution spectra, and molecular modeling methods (PDF) X-ray crystallographic data for compound 12 (CIF) X-ray crystallographic data for compound 47 (CIF)

\section{AUTHOR INFORMATION}

\section{Corresponding Author}

*herchelsmith.orgchem@ch.cam.ac.uk ORCID

Diego Núñez-Villanueva: 0000-0002-1005-1464

Christopher A. Hunter: 0000-0002-5182-1859

Notes

The authors declare no competing financial interest.

\section{ACKNOWLEDGMENTS}

We thank the Engineering and Physical Sciences Research Council (EP/J008044/2) and European Research Council (ERC-2012-AdG 320539-duplex) for funding. We thank Mr. Harry Adams (University of Sheffield) and Dr. Andrew Bond (University of Cambridge) for the help with X-ray crystallographic data collection and analysis.

\section{REFERENCES}

(1) (a) Watson, J. D.; Crick, F. H. Nature 1953, 171, 964. (b) Sinden, R. R. DNA Structure and Function; Academic Press: San Diego, CA, 1994.

(2) (a) Anfinsen, C. B. Science 1973, 181, 223. (b) Branden, C.; Tooze, J. Introduction to Protein Structure, 2nd ed.; Garland Science: New York, 1999. (c) Bikard, D.; Loot, C.; Baharoglu, Z.; Mazel, D. 
Microbiol. Mol. Biol. Rev. 2010, 74, 570. (d) Wells, R. D. Trends Biochem. Sci. 2007, 32, 271. (e) Burge, S.; Parkinson, G. N.; Hazel, P.; Todd, A. K.; Neidle, S. Nucleic Acids Res. 2006, 34, 5402.

(3) (a) Ellington, A. D.; Szostak, J. W. Nature 1990, 346, 818 (b) Stoltenburg, R.; Reinemann, C.; Strehlitz, B. Biomol. Eng. 2007, 24, 381. (c) Tan, W.; Wang, K.; Drake, T. J. Curr. Opin. Chem. Biol. 2004, 8,547 .

(4) (a) Blackburn, G. M.; Gait, M. J.; Loakes, D.; Williams, D. M. Nucleic Acids in Chemistry and Biology, 3rd ed.; RSC Publishing: London, 2006. (b) Conn, G. L.; Draper, D. E. Curr. Opin. Struct. Biol. 1998, 8, 278. (c) Bevilacqua, P. C.; Blose, J. M. Annu. Rev. Phys. Chem. 2008, 59, 79. (d) Rana, T. M. Nat. Rev. Mol. Cell Biol. 2007, 8, 23.

(5) (a) Kramer, R.; Lehn, J.-M.; Marquis-Rigault, A. Proc. Natl. Acad. Sci. U. S. A. 1993, 90, 5394. (b) Marquis, A.; Smith, V.; Harrowfield, J.; Lehn, J.-M.; Herschbach, H.; Sanvito, R.; Leize-Wagner, E.; van Dorsselaer, A. Chem. - Eur. J. 2006, 12, 5632. (c) Anderson, H. L. Inorg. Chem. 1994, 33, 972. (d) Taylor, P. N.; Anderson, H. L. J. Am. Chem. Soc. 1999, 121, 11538. (e) Berl, V.; Huc, I.; Khoury, R. G.; Krische, M. J.; Lehn, J.-M. Nature 2000, 407, 720. (f) Berl, V.; Huc, I.; Khoury, R. G.; Lehn, J.-M. Chem. - Eur. J. 2001, 7, 2810.

(6) (a) Tanaka, Y.; Katagiri, H.; Furusho, Y.; Yashima, E. Angew. Chem. 2005, 117, 3935. (b) Ito, H.; Furusho, Y.; Hasegawa, T.; Yashima, E. J. Am. Chem. Soc. 2008, 130, 14008. (c) Yamada, H.; Furusho, Y.; Ito, H.; Yashima, E. Chem. Commun. 2010, 46, 3487. (d) Yashima, E.; Ousaka, N.; Taura, D.; Shimomura, K.; Ikai, T.; Maeda, K. Chem. Rev. 2016, 116, 13752.

(7) (a) Sánchez-Quesada, J.; Seel, C.; Prados, P.; de Mendoza, J.; Dalcol, I.; Giralt, E. J. Am. Chem. Soc. 1996, 118, 277. (b) Bisson, A. P.; Carver, F. J.; Eggleston, D. S.; Haltiwanger, R. C.; Hunter, C. A.; Livingstone, D. L.; McCabe, J. F.; Rotger, C.; Rowan, A. E. J. Am. Chem. Soc. 2000, 122, 8856. (c) Bisson, A. P.; Hunter, C. A. Chem. Commun. 1996, 1723. (d) Gong, B.; Yan, Y.; Zeng, H.; SkrzypczakJankunn, E.; Kim, Y. W.; Zhu, J.; Ickes, H. J. Am. Chem. Soc. 1999, 121, 5607. (e) Gong, B. Synlett 2001, 582. (f) Zeng, H.; Miller, R. S.; Flowers, R. A.; Gong, B. J. Am. Chem. Soc. 2000, 122, 2635. (g) Gong, B. Acc. Chem. Res. 2012, 45, 2077. (h) Yang, Y.; Yang, Z.-Y.; Yi, Y.-P.; Xiang, J.-F.; Chen, C.-F.; Wan, L.-J.; Shuai, Z.-G. J. Org. Chem. 2007, 72, 4936. (i) Chu, W.-J.; Yang, Y.; Chen, C.-F. Org. Lett. 2010, 12, 3156. (j) Chu, W.-J.; Chen, J.; Chen, C.-F.; Yang, Y.; Shuai, Z. J. Org. Chem. 2012, 77, 7815. (k) Archer, E. A.; Krische, M. J. J. Am. Chem. Soc. 2002, 124, 5074. (1) Gong, H.; Krische, M. J. J. Am. Chem. Soc. 2005, 127, 1719.

(8) (a) Dervan, P. B.; Burli, R. W. Curr. Opin. Chem. Biol. 1999, 3, 688. (b) Renneberg, D.; Dervan, P. B. J. Am. Chem. Soc. 2003, 125, 5707. (c) Dervan, P. B.; Doss, R. M.; Marques, M. A. Curr. Med. Chem.: Anti-Cancer Agents 2005, 5, 373. (d) Doss, R. M.; Marques, M. A.; Foister, S.; Chenoweth, D. M.; Dervan, P. B. J. Am. Chem. Soc. 2006, 128, 9074. (e) Meier, J. L.; Yu, A. S.; Korf, I.; Segal, D. J.; Dervan, P. B. J. Am. Chem. Soc. 2012, 134, 17814.

(9) (a) Gellman, S. H. Acc. Chem. Res. 1998, 31, 173. (b) Hill, D. J.; Mio, M. J.; Prince, R. B.; Hughes, T. S.; Moore, J. S. Chem. Rev. 2001, 101, 3893. (c) Goodman, C. M.; Choi, S.; Shandler, S.; DeGrado, W. F. Nat. Chem. Biol. 2007, 3, 252. (d) Guichard, G.; Huc. Chem. Commun. 2011, 47, 5933. (e) Juwarker, H.; Suk, J.-m.; Jeong, K.-S. Chem. Soc. Rev. 2009, 38, 3316. (f) Gan, Q.; Ferrand, Y.; Bao, C.; Kauffmann, B.; Grélard, A.; Jiang, H.; Huc, I. Science 2011, 331, 1172. (g) Gopalakrishnan, R.; Frolov, A. I.; Knerr, L.; Drury, W. J., III; Valeur, E. J. Med. Chem. 2016, 59, 9599.

(10) (a) Chandramouli, N.; Ferrand, Y.; Lautrette, G.; Kauffmann, B.; Mackereth, C. D.; Laguerre, M.; Dubreuil, D.; Huc, I. Nat. Chem. 2015, 7, 334. (b) Lautrette, G.; Wicher, B.; Kauffmann, B.; Ferrand, Y.; Huc, I. J. Am. Chem. Soc. 2016, 138, 10314.

(11) (a) Stross, A. E.; Iadevaia, G.; Hunter, C. A. Chem. Sci. 2016, 7, 94. (b) Iadevaia, G.; Stross, A. E.; Neumann, A.; Hunter, C. A. Chem. Sci. 2016, 7, 1760. (c) Stross, A. E.; Iadevaia, G.; Hunter, C. A. Chem. Sci. 2016, 7, 5686. (d) Núñez-Villanueva, D.; Hunter, C. A. Chem. Sci. 2017, 8, 206.

(12) (a) Hunter, C. A. Angew. Chem., Int. Ed. 2004, 43, 5310. (b) Calero, C. S.; Farwer, J.; Gardiner, E. J.; Hunter, C. A.; Mackey,
M.; Scuderi, S.; Thompson, S.; Vinter, J. G. Phys. Chem. Chem. Phys. 2013, 15, 18262.

(13) (a) Adrian, J. C.; Wilcox, C. S. J. Am. Chem. Soc. 1991, 113, 678. (b) Adrian, J. C.; Wilcox, C. S. J. Am. Chem. Soc. 1992, 114, 1398.

(14) Krishnamurthy, V. M.; Semetey, V.; Bracher, P. J.; Shen, N.; Whitesides, G. M. J. Am. Chem. Soc. 2007, 129, 1312.

(15) (a) Paffen, T. F. E.; Ercolani, G.; de Greef, T. F. A.; Meijer, E. W. J. Am. Chem. Soc. 2015, 137, 1501. (b) Teunissen, A. J. P.; Paffen, T. F. E.; Ercolani, G.; de Greef, T. F. A.; Meijer, E. W. J. Am. Chem. Soc. 2016, 138, 6852 .

(16) Hubbard, T. A.; Brown, A. J.; Bell, I. A. W.; Cockroft, S. L. J. Am. Chem. Soc. 2016, 138, 15114.

(17) (a) Misuraca, M. C.; Grecu, T.; Freixa, Z.; Garavini, V.; Hunter, C. A.; van Leeuwen, P. W. N. M.; Segarra-Maset, M. D.; Turega, S. M. J. Org. Chem. 2011, 76, 2723. (b) Hunter, C. A.; Misuraca, M. C.; Turega, S. M. J. Am. Chem. Soc. 2011, 133, 582. (c) Hunter, C. A.; Misuraca, M. C.; Turega, S. M. J. Am. Chem. Soc. 2011, 133, 20416. (d) Hunter, C. A.; Misuraca, M. C.; Turega, S. M. Chem. Sci. 2012, 3, 2462. (e) Hunter, C. A.; Misuraca, M. C.; Turega, S. M. Chem. Sci. 2012, 3, 589. (f) Sun, H.; Hunter, C. A.; Navarro, C.; Turega, S. J. Am. Chem. Soc. 2013, 135, 13129. (g) Adams, H.; Chekmeneva, E.; Hunter, C. A.; Misuraca, M. C.; Navarro, C.; Turega, S. M. J. Am. Chem. Soc. 2013, 135, 1853.

(18) (a) Murray, T. J.; Zimmerman, S. C. J. Am. Chem. Soc. 1992, 114, 4010. (b) Zimmerman, S. C.; Murray, T. J. Tetrahedron Lett. 1994, 35, 4077.

(19) Hunter, C. A.; Anderson, H. L. Angew. Chem., Int. Ed. 2009, 48, 7488.

(20) MacroModel, version 9.8; Schrödinger, LLC, New York, 2014. 